\title{
El dinero fuente de pecados en el Inferno de Dante y en la traducción de Pedro Fernández de Villegas (Burgos, 1515)
}

\author{
Roberto MONDOLA \\ Università degli Studi di Napoli “L’Orientale” \\ rmondola@unior.it
}

\begin{abstract}
RESUMEN
El trabajo se centra en el análisis de los pecados relacionados con el dinero en el Inferno de Dante y en la primera traducción castellana de la primera cantiga de la Commedia, obra del arcediano de Burgos Pedro Fernández de Villegas. La traducción, compuesta en coplas de arte mayor y acompañada de un enciclopédico comentario, se publicó en 1515. Particular atención se dedica a la reflexión sobre el problema del mal uso del dinero que Villegas desarrolla en la glosa de los cantos en que con más vigor se levanta la voz de Dante para denunciar la gravedad del pecado de la sed de riquezas. Se analiza la postura del traductor español ante el tema comparándola no sólo con la de Dante sino también con la de Cristoforo Landino, autor del Comento sopra la Comedia, obra exégetica que se publicó por primera vez en Florencia en 1481 y que representó el punto de referencia privilegiado de Villegas.
\end{abstract}

Palabras clave: Dante, Fernández de Villegas, Traducción, Dinero

\begin{abstract}
The essay focuses on the analysis of the sins related to money in Dante's Inferno and in the first Spanish translation of the first part of the Commedia, written by Pedro Fernández de Villegas, archdeacon of Burgos. The translation, written in coplas de arte mayor, was published in 1515 with a huge commentary. The work analyses in detail Villegas' reflection on the problem of the bad use of money which reflects Dante's point of view about men's thirst of wealth. The work compares the Spanish translator's approach to the theme not only with Dante's ones but also with the words of Cristoforo Landino, author of the Comento sopra la Comedia, published for the first time in Florence in 1481, which represented an essential reference point for Villegas.
\end{abstract}

Key words: Dante, Fernández de Villegas, translation, money 
I. El objetivo de este trabajo es la valoración de los pecados relacionados con el dinero en el Inferno de Dante y la acogida que el tema recibe en la traducción castellana de la primera cantiga de la Commedia - acompañada de un monumental comentario - del arcediano de Burgos Pedro Fernández de Villegas (1453-1536), compuesta en coplas de arte mayor y publicada en $1515^{1}$. Es evidente que mi intento no es proponer lecturae dantis de los cantos del Inferno que atañen al problema del dinero, pues contamos con enjundiosas exégesis que en muchos casos han sabido desentrañar las numerosas oscuridades del poema; lo que me propongo es analizar la postura que ante el problema del dinero y del mal uso del dinero, uno de los ejes principales del Inferno, adoptó Villegas en la traducción y, por supuesto, en su poderoso comentario ${ }^{2}$, cuyo modelo principal es el Comento sopra la Comedia de Cristoforo Landino, publicado en 1481 en la Florencia de Lorenzo il Magnifico, donde florecía el culto al máximo poeta de la ciudad ${ }^{3}$.

En el Inferno son los cantos VII (el de los avaros y pródigos), XVII (donde aparecen los usureros), XIX (el de los papas simoníacos), XXI (primer canto dedicado a los barateros) y XXX (donde se hallan los falsificadores) los momentos en los cuales más alta se levanta la voz de Dante para denunciar la gravedad del pecado de la sed de riquezas, aunque también el primer canto, con la aparición de la loba hambrienta, símbolo de la codicia que el Lebrel expulsará para regenerar al mundo, revela que en la concepción dantesca el deseo ardiente del dinero es la amenaza más peligrosa que afecta a la humanidad. Así, pues, en el Inferno no hay sólo una categoría de pecadores relacionados con el dinero: si avaros y pródigos forman parte de los incontinentes fuera de la ciudad infernal de Dite, los usureros son una categoría de violentos, mientras que barateros, simoniacos y falsificadores pertenecen al amplio grupo de fraudulentos.

Como Dante denuncia vigorosamente, la codicia desenfrenada es un problema general de su época, que afecta tanto a los mercaderes como a los letrados, tanto a los miembros de la nobleza como a los religiosos ${ }^{4}$, aunque la lectura de Inferno VII e Inferno XIX demuestra que el poeta pone especial énfasis en condenar a los eclesiásticos: desear el dinero es la antítesis de la misión espiritual de la Iglesia, cuya obligación es rechazar cualquier forma de enriquecimiento material. La firme condena dantesca de un mal tan arraigado en la Iglesia es de gran interés en nuestro

\footnotetext{
${ }^{1}$ P. Fernández de Villegas (1515).

${ }^{2}$ Sobre este aspecto véase J. Rodríguez Velasco (2001); a propósito de la relación entre los versos y la glosa en el volumen burgalés, véase E. Sánchez García-R. Mondola (2011), pp. 1393-1394.

${ }^{3}$ Sobre el Comento de Landino y sobre la recepción de la obra de Dante entre Humanismo y Renacimiento, véanse entre otros M. Barbi (1890); M. Santoro (1954); C. Dionisotti (19651966); E. Garin (1970); D. Thompson (1970); R. Cardini (1973); F. La Brasca (1987); P. Procaccioli (1989); D. Parker (1993).

${ }^{4}$ A. Mariani (1970), p. 302.
} 
análisis si tenemos en cuenta que el traductor del Inferno, Villegas, fue excelente humanista y sobre todo miembro oficial del clero catedralicio burgalés: su actividad literaria, paralela y complementaria a su papel de hombre de la Iglesia, alcanzó su plena madurez en la época de los Reyes Católicos 5 .

Una abundante documentación custodiada en el Archivo de la Catedral de Burgos nos informa sobre los ascensos de Villegas, que en 1484 ya había obtenido el cargo de abad de Cervatos ${ }^{6}$ y que a la altura de 1497, tras haber vivido en Italia aproximadamente desde la segunda mitad de 1484 hasta 1487 - periodo en que, respirando el aire culto de los elegantes ambientes humanistas de Roma y Florencia, en su alma empieza a brotar el germen del interés por Dante ${ }^{7}$ - fue nombrado arcediano de Burgos ${ }^{8}$, cargo que mantendrá hasta los últimos años de su vida ${ }^{9}$.

El estrecho vínculo entre la traducción dantesca y los ambientes altoaristocráticos de la Burgos del primer Renacimiento resulta evidente si pensamos que el Infierno va dedicado a la hija natural de Fernando el Católico, doña Juana de Aragón, cuyo retrato el mismo Villegas traza en el Proemio a ella dedicado, recordando la apasionada inclinación por las letras de una mujer dantófila, una patrocinadora de cultura muy parecida a los mecenas de las cortes renacentistas italianas ${ }^{10}$.

Como ya hemos adelantado, la traducción de Villegas va acompañada por un enciclopédico comentario cuya fuente privilegiada es la exégesis dantesca de Landino: las circunstancias en las que salen a luz el Comento y la obra de Villegas presentan ciertas analogías, si bien el erwartungshorizont de los dos textos es muy distinto. El elemento común estriba en el hecho de que tanto Lorenzo il Magnifico

\footnotetext{
${ }^{5}$ Para un perfil biográfico de Villegas, véase R. de Floranes (1851). Sobre su traducción del Inferno, véanse A. Beltrani (1915); R. Recio (1999); C. Alvar- J. M. Lucía Megías (2009), pp. 96-99; R. Mondola (2011); C. Hamlin (2012a); C. Hamlin (2012b); C. Hamlin (2012c). Entre los estudios sobre la traducción de Villegas y su relación con otras versiones españolas del poema dantesco, véanse: A. Farinelli (1922); J. Arce (1965); M. Penna (1965); P. Russell (1985), pp. 34-35; C. Alvar (1990); M. L. López Vidriero, E. Santiago Paez (1992); M. Carrera Díaz (1992).

${ }^{6}$ Lo atestigua un documento del 1 de marzo de 1484. Archivo Histórico de la Catedral de Burgos, RR 21, fol. 380.

${ }^{7}$ El periodo italiano de Villegas se reveló fundamental para el conocimiento de la Comedia, pues en el Prohemio el traductor señala que "tobe alguna pequeña notiçia mientra resedí en la corte romana”.

${ }^{8}$ El primer testimonio del arcedianato de Villegas es un documento del 9 de octubre de 1497. Archivo Histórico de la Catedral de Burgos, Lib. 77, ff. 573-575.

${ }^{9}$ Contamos con otro escrito del 13 de agosto de 1535 - un año antes de su muerte, ocurrida el 6 de diciembre de 1536 - en el que por última vez Villegas es nombrado arcediano de Burgos. Archivo Histórico de la Catedral de Burgos, Lib. 59, ff. 123-128.

${ }^{10}$ Sobre este aspecto, véase R. Mondola (2011), pp. 25-28.
} 
como doña Juana patrocinan la publicación de los textos de Landino y Villegas, considerando una edición de la obra de Dante vehículo privilegiado para exaltar el prestigio cultural de sus respectivas ciudades: Florencia, cuna del Renacimiento italiano, y Burgos, antigua capital del Reino de Castilla.

A pesar de eso, son inmensas las distancias entre ambas situaciones. El Comento es uno de los frutos más prestigiosos del Neoplatonismo, que en la Florencia de la segunda mitad del siglo XV desplaza a las corrientes filosóficas de la Edad Media ${ }^{11}$ : los intelectuales neoplatónicos, entre los cuales destaca Landino, son los nuevos apóstoles del Humanismo, movidos por una voluntad de laicización del arte. Como atestiguan algunos apartados del paratexto del Comento, las raíces neoplatónicas son los pilares sobre los que Landino edifica su exégesis dantesca y es en este aspecto donde estriba la originalidad de su glosa, que se aleja de los comentarios anteriores y busca en los tercetos de la Commedia significados ocultos y misteriosos ${ }^{12}$. En cambio, la lectura del poema dantesco de Villegas demuestra una continua preocupación por el respeto del dogma, reveladora de una patente adhesión a las raíces más profundas del humanismo burgalés, cuya figura más relevante, Alfonso de Cartagena, está “obsesionado por la moderación y el respeto a los valores establecidos dentro del Cristianismo oficial” ${ }^{\text {13 }}$.

Si en la glosa castellana la profunda inspiración neoplatónica queda sofocada, el elemento de la operación cultural landiniana que Villegas hereda es el que podemos considerar "político", eje del paratexto florentino y del comentario burgalés. En el Comento, muchas de las páginas que preceden a los cantos dantescos, del todo ajenas a la costumbre medieval del accessus auctoris ${ }^{14}$, se construyen como una exaltación propagandística de la lengua y de la cultura florentina y de su hegemonía en el panorama italiano. Si Landino ensalza la centralidad del papel de la Signoria Medicea en la Italia de finales del siglo XV, una parte del apartado paratextual (me refiero a la epístola de Marsilio Ficino) desarrolla el motivo de la restitutio Dantis, celebrando la vuelta triunfal a Florencia de su supremo poeta, cuyo poema por primera vez se imprime en la ciudad ${ }^{15}$. También en Villegas la recaída propagandística de la obra es evidente, pues la glosa burgalesa es una apología de la

11 Sobre el neoplatonismo landiniano véanse E. Garin (1994), pp. 100-105; C. Landino (2001), pp. 56-59.

${ }^{12}$ Como bien señala Procaccioli hablando de Landino, "tutto, nella sua lettura è subordinato sistematicamente - platonicamente - a altri e più alti significati”. C. Landino (2001), p. 80.

${ }^{13}$ F. J. Peña Pérez (2007), p. 242.

${ }^{14}$ Sobre el accessus auctoris véase E. A. Quain (1986).

${ }^{15}$ A este respecto cabe recordar que las primeras ediciones impresas de la Comedia salieron en 1472, en Foligno, Mantova y Venecia. En 1477 en Venecia se publica la primera edición del poema acompañada de un comentario (el de Lana, del siglo XIV). En 1478 salen a luz otras ediciones, en Nápoles, Venecía y Milán, así que el Comento es la primera Comedia impresa en Florencia. 
misión política e ideológica de Fernando el Católico, el Rey capaz de poner fin a la Reconquista y de inaugurar una época de expansión exterior que llevaría a España a alcanzar la primacía europea ${ }^{16}$.

Un cotejo entre el Comento y la glosa de Villegas demuestra que el arcediano de Burgos, si por un lado recoge muchos elementos que propone Landino, por otro reelabora el texto del humanista toscano según su ideología católica, añadiendo citas y referencias cuando la interpretación que le proporciona su fuente le parece pobre, cortando u omitiendo algunos pasajes cuando la glosa italiana es en su opinión demasiado prolija. El porcentaje de citas de la Sagrada Escritura y de los Padres de la Iglesia, notablemente mayor en la glosa castellana, es el mejor testimonio de la tendencia de Villegas a utilizar el Inferno para divulgar los preceptos de la doctrina católica y esta razón lo empuja a reprochar algunas veces a Dante cuando, en su opinión, se ha apartado del dogma abandonándose a una excesiva tendencia a la poetización ${ }^{17}$.

Así, pues, la lectura de la exégesis de Villegas es reveladora de una dinámica de personal apropiación y adaptación del texto landiniano y de una voluntad de divulgación y enseñanza: las numerosas referencias - ausentes en Landino - de auctores latinos (de Cicerón a Horacio, de Séneca a Juvenal), de autoridades italianas (Guido delle Colonne o Leonardo Bruni entre otros) y sobre todo las continuas citas de la Biblia y de los textos de los Padres de la Iglesia cumplen con la función de avalar la validez de la argumentación, revelando la madura autonomía de Villegas. Su didacticismo conjuga la ortodoxia cristiana con la sabiduría de los clásicos grecolatinos, sin olvidarse del mundo del mito: en una óptica típicamente humanística Villegas manifiesta la convicción de que bajo las vestiduras de sus legendarias ficciones, fuente de provechosos principios ${ }^{18} \mathrm{y}$ muestra de una primitiva teología, se esconden verdades de alcance divino ${ }^{19}$.

II. Antes de analizar el tratamiento del tema del dinero en Dante y Villegas, creo que no es inútil comprobar cuántas veces la palabra danaro aparece en el texto italiano: sólo en dos casos, porcentaje muy escaso, y precisamente en la quinta

\footnotetext{
${ }^{16}$ Sobre este aspecto véase R. Mondola (2011), pp. 54-64.

17 Como a propósito de la injusta colocación de algunos dañados en el Limbo, de la presencia de Dido en el círculo de los lujuriosos o de la escasa presencia de los diablos en la representación dantesca. Sobre este aspecto véase R. Mondola (2011), pp. 64-68.

${ }^{18}$ Lo demuestran claramente las palabras de Villegas en la glosa de la copla VI del canto IX, cuando hablando de las tres Furias, nota que "los poetas, debaxo de sus graciosas ficiones, ponen mucha doctrina de theología prática y moral”. En el mismo canto (glosa de la copla IX) la amonestación de Virgilio a Dante a que no vea la cara de Medusa encierra una enseñanza "de notables moralidades y provechosas para las buenas costumbres".

${ }^{19}$ Sobre las fábulas poéticas consideradas muestra de una antigua teología véase E. Garin (1981), pp. 52-68.
} 
bolsa del octavo círculo, donde se hallan los que practicaron la baratería ${ }^{20}$. En Inferno XXI, vv. 41- 42, leemos que en la ciudad de Lucca

ogn'uom v'é barattier, fuor che Bonturo

del no, per li denar, vi si fa ita.

Luego, en el canto XXII, el truhán Ciampolo di Navarra recuerda que frate Gomita, el "vasel d’ogne froda", “danar si tolse e lasciolli di piano" (v. 85). En la traducción de Villegas, por supuesto limitando el recuento a los versos de arte mayor, la palabra "dinero" aparece cuatro veces: además de las traducciones, bastante fieles, tanto de los vv. 41-42 del canto XXI,

excepto Bonturo, el de Santa Cita, ado por dineros del no fazen ita (VIfg)

como del v. 85 del canto XXII:

llevando dineros les daba de mano (XIIf)

el arcediano de Burgos emplea el sustantivo otras dos veces. En la traducción del canto XIX papa Nicolás III afirma que

Nascí de la ossa y por sus descendidos, en más encumbrar los robaba el dinero (XIab)

En el canto XXXII Bocca degli Abati recuerda que Buoso da Duera, traidor de la patria que se encuentra con él en Antenora

llora el dinero con voz desonesta (XVIIc)

Cotejando el texto castellano con el original, salta a la vista una falta de variedad léxica por parte del traductor, pues en las dos ocasiones en que Villegas usa la palabra "dinero" por su cuenta, el vocablo traduce avere ("che sú l'avere e qui me misi in borsa", If. XIX, 72) y el galicismo argento ("El piange qui l'argento de' Franceschi, If. XXXII, 115).

Respecto a la voz oro, cabe decir que en Dante el término tiene, en línea general, un valor semántico mucho más positivo que danaro, posee un mayor carácter de nobleza y no se liga sólo a la idea de la ganancia ${ }^{21}$. En el Inferno el vocablo aparece

20 A. Mariani (1970), p. 302.

${ }^{21}$ Por ejemplo, es de "fin oro" la cabeza del Viejo de Creta, la estatua que Virgilio describe en Inferno XIV (vv. 94-120) y de cuyas lágrimas tienen origen los ríos infernales. 
a menudo, aunque en la traducción castellana se encuentra tan sólo tres veces. Sin duda, es el canto XIX el más interesante por lo que respecta al tratamiento de la palabra, pues aquí Dante utiliza hasta tres veces la fórmula "per oro e per argento" (v. 4, v. 95 y v. 112) que, como señala Roberto Mercuri ${ }^{22}$, hay que considerar como un binomio léxico, con el que el poeta florentino hace hincapié en la diferencia abismal entre los pontífices de su época y san Pedro, el primer papa "sanz'oro e sanz'argento" (Par. XXII, 88). Veamos cómo traduce Villegas estos versos: en el primer caso Dante dice que los secuaces de Simón Mago adulteran "le cose di Dio" "per oro e per argento", única vez que la fórmula aparece en castellano ("por oro y argento"23). En el segundo caso (v. 94), al comienzo de su durísima invectiva contra la avaricia de los papas, Dante recupera un suceso narrado en los Actos de los Apóstoles (I 13-26), es decir, que ni Pedro ni los otros apóstoles pidieron nunca "oro od argento" a Matías: "Né Pier né li altri tolsero a Matía/ oro ed argento", mientras que en la traducción aparece una pregunta retórica, pues leemos: "me di si estobieron en tanto o en cuanto" (XVd), verso cuyo sentido Villegas aclara en la glosa, recordando que los apóstoles no se comportaron como los mercaderes que "compran y venden" ${ }^{24}$. Sin duda, es el tercer caso el que determina, por la omisión de la palabra oro, un indudable empobrecimiento expresivo: en el v. 112, Dante reprocha explícitamente a los simoníacos diciendo "Fatto v'avete dio d'oro e d'argento", reminiscencia bíblica de Oseas VIII 4, “argentum suum et aurum suum fecerunt sibi idola". En cambio la traducción burgalesa reza "y que otro es fazer dioses de argento" (XVIIf), así que el eco de la Sagrada Escritura se pierde totalmente; el empobrecimiento no atañe sólo a los versos, sino también al comentario, ya que falta la referencia a la Sagrada Escritura, mientras que Landino correctamente la señala ${ }^{25}$.

Finalmente, la palabra "moneda” aparece sólo una vez en el texto castellano, también en el canto XIX, "ternás bien guardada la falsa moneda” (XVf), traducción bastante literal del v. 98 del original, "e guarda ben la mal tolta moneta".

III. Veamos con más detalle las articulaciones del tema del dinero en Dante. Ya a partir del canto $\mathrm{I}^{26}$, al narrar la visión de las tres fieras que impedían su camino, el poeta hace hincapié en la gravedad de la codicia, representada por la loba,

\footnotetext{
${ }^{22}$ R. Mercuri (2007), p. 351.

${ }^{23}$ Copla I.

${ }^{24}$ Copla XV.

${ }^{25}$ Comento, cit., II, p. 765.

${ }^{26}$ Por evidentes razones no puedo proponer un elenco completo de la bibliografía sobre el canto I del Inferno. Entre las lecturae más notables me limito a recordar Z. G. Baranski (1987); M. Aversano (1992); Z. G. Baranski (2012).
} 
poniéndose en la estela de san Pablo, que en la primera a Timoteo (I Tim. VI 10) había afirmado que la codicia es raíz de todos los males. En la concepción dantesca, con la que el arcediano de Burgos concuerda totalmente, es la sed de riquezas lo que realmente aflige a la humanidad: los versos en arte mayor presentan al respecto una variación interesante, pues si Dante dice que la loba "molte genti fé giá viver grame" (If. I 51), el traductor afirma que la bestia ha guiado al hombre "al falso interese", señalando en la glosa que "falso y mintroso es el interese de las riquezas y bienes mundanos" ${ }^{27}$.

El comentario del primer canto es revelador de una de las peculiaridades de la obra burgalesa: Villegas aprovecha su reflexión acerca del dinero para acercar el texto dantesco al público de la Castilla del primer tercio del siglo XVI. Hablando de los daños que causa la codicia, el arcediano de Burgos inserta una interesante actualización, una referencia a la contemporaneidad española, precisamente a la colonización de las Américas, que en su opinión lleva consigo la perniciosa tendencia a buscar únicamente el oro. El tono del arcediano de Burgos contra los que se hacen encandilar por el espejismo de las riquezas es muy firme, cuando insiste en que continuamente se ve que muchos colonizadores "cada día van a las Antillas a Calicut a los últimos fines de la tierra a buscar este maldito de oro" ${ }^{28}$. Es notable aquí la sensibilidad del arcediano de Burgos, interesado en afirmar el punto de vista eclesiástico sobre un tema muy actual en España en la época de los primeros viajes hacia el Nuevo Mundo: en el diario de Cristóbal Colón, como señala Pierre Vilar, el texto referido al periodo que va desde el 12 de octubre de 1492 hasta el 17 de enero de 1493 presenta al menos 65 referencias a la palabra oro $^{29}$, clara, aunque en cierta medida ingenua, señal de cómo la búsqueda del oro es una preocupación que acuciaba insistentemente a los colonizadores. Además, si nos ceñimos a los años en los que Villegas se dedicó a su comentario dantesco, cabe recordar que entre 1511 y 1520 se registra la máxima llegada de oro del primer tercio del siglo XVI, 9153 kilos $^{30}$.

Está claro que la condena de Villegas no es una voz aislada: la obsesión de una riqueza concebida sólo como una forma transportable de oro y botín, la falta de un plan adecuado para invertir en España como en los territorios de ultramar, el riesgo de que en el Nuevo Mundo se trasplantasen las atrasadas y a menudo improductivas estructuras económicas de la Castilla tardomedieval ${ }^{31}$ son vistos por el arcediano de

${ }^{27}$ Copla VII.

${ }^{28}$ Canto I, copla IX.

${ }^{29}$ Sobre este aspecto, véase P. Vilar (1971), pp. 81-105.

${ }^{30}$ P. Vilar (1971), p. 86.

${ }^{31}$ A este respecto John Elliott recuerda que "cuando Cortés desembarcó en la costa oriental de México en 1519, muchos de los rasgos característicos de la sociedad castellana de la Reconquista ya se habían reproducido al otro lado del Atlántico: la rapiña, el pillaje, la esclavización y la explotación bajo el signo de la cruz”. J. H. Elliott (2010), p. 159. 
Burgos como un peligro, en el que insistirán un poco más adelante muchos intelectuales y cronistas en la época de Carlos V. En opinión de Villegas, el deleite que provocan las riquezas es efímero, poco duradero, mentiroso y engañador: si los bienes mundanos prometen descanso y felicidad, acaban provocando "trabajo en logar de contentamiento [...] congoxa por seguridad"32.

IV. Después de la aparición de la loba, el primer canto estrechamente relacionado con el problema del dinero es el séptimo, donde aparecen los avaros y pródigos, personajes anónimos, sin una identidad histórica definida ${ }^{33}$. Es éste un detalle revelador de una tendencia importante: en los cantos cuyo tema es el dinero, no hay personajes que llamen la atención de Dante y con los que el viator sienta la necesidad de establecer un verdadero diálogo. Como muestra de eso, bastaría con recordar que en el canto VII hay una masa indeterminada de dañados o, mejor dicho, ningún personaje que merezca ser nombrado y que tome la palabra ${ }^{34}$, lo que se opone claramente a los cantos anteriores, el V, donde Dante se conmueve hasta desmayarse tras haber conocido, a través del recuerdo de Francesca da Rimini, su dramática historia de amor con Paolo Malatesta, y el canto VI, donde el glotón Ciacco aclara las dudas de Dante acerca del futuro de Florencia. También el canto XVII, el de los usureros, aparece opuesto a los anteriores, el XV y el XVI, en los que Dante encuentra a los sodomitas, en primer lugar al autor del Trésor y su antiguo maestro, Brunetto Latini, y, en segundo, a los tres florentinos ejemplos de magnanimidad Jacopo Rusticucci, Guido Guerra y Tegghiaio Aldobrandi; en cambio los usureros de Inferno XVII representan los prototipos de una bestialidad que no merece ninguna compasión. Finalmente, en el canto XXI, el de los barateros, desaparece totalmente el aire en cierto modo heroico del canto XX, el de los adivinos que, aunque no merecen la piedad, sí poseen una imagen de elegancia y sobriedad característica de los personajes de la clasicidad ${ }^{35}$. Así, pues, entre los varios pecados infernales, la baratería es sin duda el que más se aleja de la heroicidad, lo que determina la profunda repulsión de Dante, que no siente ninguna piedad por los barateros inmersos en la pez; al respecto, fue muy aguda la opinión de Paolo Soldati, que en una lectura dantis de Inferno XVII notó que "non esiste

\footnotetext{
${ }^{32}$ Canto I, copla VII. Esta misma idea según la cual la sed de riquezas provoca cansancio se encuentra en el Comento: glosando los versos en los que aparece la loba, Landino dice que "L'avaro sta sempre in affanno et per guadagnare, et per guardare el guadagnato, et per accumulare mai gode chosa acquistata”. C. Landino (2001), p. 307.

33 Sobre el canto VII del Inferno véanse M. Marti (1961); G. Getto (1966); F. Figurelli (1983); M. Aversano (1992); E. Cusani (1993); A. Baldi (1994); J. F. Vickrey (1995); G. Bardazzi (2000); G. Ledda (2012).

${ }^{34}$ R. Mercuri (2007), p. 350.

${ }^{35}$ A. Scolari (1967), p. 727.
} 
vigor di spirito che Dante rispetti nei peccati di cui è cagione o strumento il denaro"36.

En el rico y variado mundo del Inferno dantesco, muchos son los personajes que, a pesar de sus pecados, representan inolvidables ejemplos de fortaleza, pasión, coraje, coherencia, inteligencia, desde Francesca hasta Farinata degli Uberti, desde Pier delle Vigne hasta Ulixes; sin embargo, ninguna de estas virtudes se encuentra en las almas de los pecadores relacionados con el dinero. Aquí estriba una diferencia entre Dante y Villegas: aunque reconozca la culpa de los personajes y considere justo el castigo, al mismo tiempo el florentino siente una profunda turbación por la desgracia y el sufrimiento de algunos personajes, como demuestran varios encuentros con los dañados, reveladores de la inquietud moral de Dante y de la intensidad de sus sentimientos. En la traducción y en el comentario castellano, en cambio, el tono que Villegas usa para definir a los pecadores es de firme condena, sin algún elemento que en cierta medida pueda suavizar el juicio; debido a un esquematismo ideológico muy riguroso y, en segundo lugar, a una mayor e inevitable distancia emotiva respecto a los sucesos narrados en el Inferno, en Villegas no existe ningun sentimiento de compasión hacia la desgracia de los dañados.

En Inferno VII Dante presenta dos categorías de pecadores, avaros y pródigos, opuestas pero condenadas en el mismo lugar. El primer elemento que salta a la vista en la glosa castellana del canto es la equivalencia léxica que Villegas propone entre la avaricia y la codicia, vocablos tratados como sinónimos; al respecto cabe recordar que también en Dante la cupiditas equivale a la avaricia, es decir, a la sed de poseer, cuyo símbolo es la loba. Así pues, Villegas se pone en la estela de Dante, pero también de Landino que, al comienzo de su exégesis del canto, señala que "avaritia non é altro che immoderata cupiditá di possedere" ${ }^{\text {,3 }}$, idea que el humanista toscano reitera poco después, cuando, apoyándose sobre la autoridad de la pseudociceroniana Rhetorica ad Herennium, afirma que "Avaritia [...] é immoderata cupiditá d'avere" ${ }^{38}$.

Muy interesante es analizar cómo los dos vocablos se consideran en la lexicografía de la época de los Reyes Católicos: si Palencia, en su Universal vocabulario de romance en latín (1490), trata los dos términos como equivalentes:

Avaricia es demasiada cobdicia de adquirir y tener y guardar riquezas; dízese avaricia de avere que es cobdiciar. Avaro es cobdicioso de oro, hombre que jamás piensa que le baste lo que tiene y nunca cree ser lleno ${ }^{39}$.

${ }^{36}$ P. Soldati (1967), p. 569.

${ }^{37}$ C. Landino (2001), I, p. 487.

${ }^{38}$ C. Landino (2001), I, p. 494.

39 A. de Palencia (1490), fol. xxxviii. 
en la segunda y más completa edición del Vocabulario de romance en latín de Nebrija (1516) hay dos entradas de "avaricia": una es la "codicia grande” y deriva de avaritia, otra es la "escasseza" y proviene de parsimonia-ae ${ }^{40}$; por lo que se refiere a la entrada "codicia”, Nebrija señala que la palabra proviene de cupiditasatis $^{41}$.

Es evidente que para valorar la postura de Villegas acerca del problema del dinero es imprescindible la lectura de la glosa. Sin embargo, a veces también los versos en arte mayor nos proporcionan algunos detalles que llaman la atención, como algunas pequeñas amplificaciones con las que el traductor refuerza la condena de pecados relacionados con el dinero, subrayando la caducidad de todo lo que es terrenal. Si Dante afirma que la "quarta lacca” (v. 16), eso es, el círculo de los avaros y pródigos, "'l mal de l'universo tutto insacca" (v. 18), Villegas añade que allí "todas las culpas están arraigadas" (IIIh), verso que le permite recuperar otra vez en la glosa la opinión de san Pablo, según el cual la codicia es "raíz de todos los males". Poco después nuestro arcediano añade "y acá nos fatiga la sed de codicia" (IVd), haciendo hincapié en el pecado de los dañados a través de la palabra “codicia”, ausente en el texto dantesco y puesta al final del dodecasílabo español.

En opinión de Villegas la avaricia es el pecado capital del que proceden todos los demás, soberbia, envidia, ira, pereza, gula y lujuria. De cada pecado, el humanista burgalés explica el por qué de la común dependencia de la avaricia: los que poseen mucho dinero se ensoberbecen, los envidiosos desean furiosamente las riquezas ajenas, la ira pertenece a los ricos que no son adorados, la pereza es propia de los adinerados que quieren pasar la vida sin ocuparse de nada, mientras que la gula y la lujuria son consecuencias de la abundancia de bienes temporales. Quizá sea la traducción de Inferno VII la que revela más, gracias a las amplificaciones, la sensibilidad del traductor dantesco hacia el problema del dinero. En la copla XI Villegas añade una media copla de arte mayor, cuatro versos que rezan así:

pues, o miserables, cabtibos vivientes

¿por qué corréis ciegos tras lo transitorio

do vedes tan público escarnio y notorio?

¡frenad apetitos tan desobedientes! (XIefgh)

El sentido de los versos se hace más claro en la glosa: "se infiere una justa increpación y consejo que es fuera del texto del Dante y lo añedimos aquí diziendo a los tristes mortales que pues, así es, las riquezas temporales traen tantos males a la vida humana”.

40 E. A. de Nebrija (1981), p. 30.
41 E. A. de Nebrija (1981), p. 49. 
Aclarando que los versos no son fiel reproducción del texto italiano Villegas deja de ser traductor para convertirse en un predicador que, con cierta indignación, se dirige a sus lectores católicos amonestándoles para que no se dejen vencer por la sed de los bienes y placeres mundanos. A este respecto, salta a la vista el empleo del imperativo "frenad", puesto al comienzo del último verso de la copla, como si Villegas hablara desde un púlpito de una iglesia, tendencia que se repite a lo largo de la traducción, pues hay otros momentos en los que el traductor se lanza en firmes amonestaciones a su público para que se aleje de los pecados.

Sin duda, en el canto VII la atención de Dante se dirige sobre todo hacia los avaros, como confirma tanto la pregunta que el viator hace a Virgilio, "Maestro mio, or mi dimostra/ che gente é questa, e se tutti fuor cherci/ questi chercuti a la sinistra nostra” (vv. 37-39), como la elaborada respuesta de su guía (vv. 40-48). Pese a que, como queda dicho, no aparezcan nombres de individuos, la categoría de avaros está compuesta por los clérigos, que suelen desperdiciar el dinero: no hace falta fijar los rostros de los condenados, pues nos encontramos ante una costumbre pésima y al mismo tiempo universal, que no pertenece a una época determinada o a un contexto geográfico concreto. Aunque la soberbia sea el pecado original de Lucifer, la codicia es probablemente la causa de todos los males, teoría reiterada a lo largo de la glosa castellana, como demuestra esta acre invectiva de Villegas que, a pesar de ser en muchos aspectos traducción de Landino ${ }^{42}$, presenta un elemento de originalidad, ya que el arcediano de Burgos utiliza como prototipo del pecador el retrato de Catilina que Salustio traza en el Bellum Catilinae:

Desta avaricia proceden las enemistades entre padres y fijos y hermanos y amigos y de la patria [...] Ésta faze las injusticias [...] ésta los tumultos, escándalos, sediciones y guerras, ésta finche el mar de cosarios y la tierra de robadores, las cibdades y casas de ladrones nocturnos y diurnos, faze los homicidios, desvella las caras, perjurios, falsos testimonios, por ésta matan de fambre los avarientos a sus criados, a sus mugeres y fijos, a sí mismos, ésta rompe las leys, los magistrados, la pudicia y castidad, la honestidad de las viudas, la vergüença de las vírgines, ésta faze las fraudes, las simonías, las usuras, ésta [...] es la raíz de todos los males. Deste vicio es contrario otro [...] no tan digno de odio, que es la prodigalidad, del que echa a mal su fazienda y bienes usando mal dellos [...] y para fazer tales locuras y derramamientos superfluos [...] torna a fazer los actos

\footnotetext{
42 “L'avaritia suscita et commuove discordia tra congiunti di sangue, d'amicitia, et di patria. L'avaritia produce ingiustizia, dalla quale s'excitano tumulti, sedizioni, et guerre civili. L'avaritia è cagione delle guerre externe. L'avaritia riempie el mare di parate et di corsali, et le strade di ladroni. L'avaritia produce nella città furti, homicidii, veleni, periurii, falsi testimonii, iudici corropti. Finalmente fa el padre della famiglia crudele inimico alla moglie, et a' figliuoli, et a sé medesimo, perché per paura di non consumare el ragunato defrauda delle chose necessarie sé e tutta la famiglia. Vende le leggi e’ magistrati. Vende la pudicitia et la castità”. C. Landino (2001), II, p. 488.
} 
contrarios suyos y pertenescientes al avaro, rapinando y defraudando y robando [...] como dize el Salustio de Lucio Cathilina, que era fambriento de lo ageno y derramador de lo suyo, y porque estos dos vicios [...] aunque contrarios y diferentes son acerca de las riquezas y bienes temporales [...] justa cosa es ser punidos en un mesmo cerco y tormento ${ }^{43}$.

Esta libertad de Villegas respecto a su modelo abona su vocación humanista y es una buena muestra de su notable conocimiento de las fuentes del mundo clásico que utiliza: su referencia es muy precisa, como demuestra la frase "fambriento de lo ageno y derramador de lo suyo”, traducción fiel del “alieni adpetens, sui profusus” de Salustio (Bellum Catilinae V).

A pesar de la común colocación en el cuarto círculo, para Villegas los avaros son peores que los pródigos, pues el arcediano de Burgos nota que "El vicio y culpa de la prodigalidad consiste en el mal usar y expender la pecunia y bienes temporales; es vicio contrario a la avaricia [...] no digno de tanto odio"44. Apoyándose en la autoridad de la Sagrada Escritura, Villegas señala que tanto la avaricia como la prodigalidad se alejan de la virtud de la liberalidad, pero

el pródigo le es menos contrario, porque la liberalidad consiste en dar cuando y como y que y a do se deve. El avaro no da y éste del todo es contrario, el pródigo da más de lo que deve y cuando y como no deve, mas pues da, alguna conformidad tiene con el liberal ${ }^{45}$.

Más allá de la diferencia entre avaros y pródigos, hay una más sutil distinción entre los avaros, que se limitan a ofenderse a sí mismos, y los clérigos avarientos, que hieren y traicionan su oficio y su sagrada misión. Villegas, hombre de la iglesia, comparte con Dante la opinión según la cual la avaricia en los clérigos es un pecado mucho más grave que en los laicos:

los clérigos son más culpados de la avaricia porque no tienen tanta necessidad de ser avaros, que la vida y mantenimiento suyo tienen más seguro con sus rentas ecclesiásticas que tienen abundantemente [...] y por eso en el guardar las riquezas son más culpados y sin dubda muchos dellos en esto lo son, queriendo y amando el dinero más de quanto les conviene, pues cada día tienen renta y obladas y décimas, podían más sueltamente ser liberales ${ }^{46}$.

Al mismo tiempo, si Dante vitupera la general difusión del pecado de la avaricia entre los miembros de la Iglesia, Villegas se vuelca en defender a los eclesiásticos que no desperdician los bienes: "muchos hay virtuosos y notables varones que usan

\footnotetext{
${ }^{43}$ Canto VII, copla I.

${ }^{44}$ Canto VII, copla VI.

${ }^{45}$ Canto VII, copla VI.

${ }^{46}$ Canto VII, copla VI.
} 
de liberalidad a donde y como conviene y fazen muchas limosnas y notables edificios de iglesias y capillas y monesterios" ${ }^{\prime 7}$. Está claro que hay que condenar a los que guardan el dinero por su bien, pero en opinión de Villegas hay ejemplos de eclesiásticos virtuosos que atesoran las riquezas para la utilidad pública y que por eso no pueden ser reprobados ${ }^{48}$.

Si el texto dantesco deja entender claramente que el pecado de los clérigos es en primer lugar el de la avaricia, Villegas propone un análisis en cierto modo casuístico, precisando que sobre todo los miembros más jóvenes de la Iglesia son los culpables de prodigalidad:

los clérigos (especialmente moços) suelen pecar en el otro contrario vicio que es de la prodigalidad, gastando en usos profanos y malos más de quanto conviene a su honestidad y religión clerical, expendiendo los bienes ecclesiásticos en malos usos, que eran sobrándoles para los pobres ${ }^{49}$.

V. Por lo que respecta a los que malgastan el dinero, fundamental en la estructuración del Inferno dantesco es la distinción entre los pródigos y los derrochadores: si los primeros se encuentran junto a los avaros fuera de la ciudad de Dite, los segundos se hallan más en profundidad, pues pertenecen, al igual que los suicidas, a la categoría de los violentos contra sí mismos (canto XIII). Como Virgilio aclara en Inferno XI (vv. 40-41), lo que distingue a los derrochadores es la violencia con la que destruyen sus bienes: "Puote omo avere in sé man violenta/ e ne’ suoi beni”. En su exégesis, también gracias al Comento, Villegas recoge esta distinción, ya que comentando estos versos señala que:

Es de notar que arriba este auctor [...] puso en contrario vicio la prodigalidad y a los pródigos que se topavan y atormentaban con los avarientos; agora pone aquí con estos violentos y injuriadores de sí mesmos a los que echaron a mal sus bienes, que llaman los derechos "dilapidadores" y “destruidores", así que éstos son diferentes y muy peores que los pródigos y aquéllos pecaron en dar demasiado y sin medida con prodigalidad, éstos destruyeron sus faziendas echándolas a mal ${ }^{50}$.

Como se evidencia, los que los derechos llaman “dilapidadores” o "destruidores", es decir, los derrochadores, representan una categoría mucho peor que la de los

\footnotetext{
${ }^{47}$ Canto VII, copla VI.

48 "los perlados y personas eclesiásticas que tienen grandes rentas pueden [...] guardar sus pecunias y tenerlas para las tales públicas utilidades o para fazer obras pías o otras distribuciones provechosas de que Dios y la república se sirva”. Canto VII, copla VI.

${ }^{49}$ Canto VII, copla VI.

${ }^{50}$ Canto XI, copla VII.
} 
pródigos y se distinguen de aquellos por la rapidez con que desperdician sus riquezas: "los pródigos van consumiendo sus bienes gastándolos mal y poco a poco se fallan al fin y al fondón de sus sustancias, mas estos dilapidadores [...] más presto abrevian sus negocios" ${ }^{\prime 51}$.

A diferencia del Comento, la glosa burgalesa hace hincapié en la categoría de los que derrocharon sus bienes, compuesta por los jugadores "diabólicos y furiosos que anochecen ricos y amenecen pobres", los que "en una noche o en un día juegan quanto tienen y son destruidores supitos de sus haziendas, quedando perdidos ellos y sus casas" ${ }^{2}$. El tema de los que deciden gastar el dinero en el juego, ausente en Landino, despierta la preocupación de Villegas, que al asunto dedica un largo discurso, apoyándose como de costumbre en la autoridad de la Sagrada Escritura. Sumamente interesante es a la argumentación que desarrolla Villegas, tanto en el canto XI como en el XIII, un discurso que, además de actualizar el texto dantesco y acercarlo al público de la Castilla contemporánea, nos explica por qué en la concepción del arcediano de Burgos los dilapidadores equivalen a los jugadores: "esta maldad tan abominable y peligrosa [...] se usa mucho en nuestros tiempos, que hemos visto faziendas gruesas en muchos tiempos fundadas y trabajadas en un punto perdidas por juegos de mancebos que las heredaron" ${ }^{33}$.

A este respecto, hay que recordar que en la Burgos del XVI el juego dejó de ser una actividad de diversión para convertirse en un grave problema, una verdadera epidemia social que preocupó a los poderes públicos. Entre finales del siglo XV y las primeras décadas del XVI varias provisiones reales (en 1484, 1492 y 1514) prohibieron "todo tipo de juegos de naipes, dados y lugares de juego" ${ }^{, 4}$ con el objetivo de perseguir a los que practicaban juegos ilícitos. Cuatro años después de la traducción de Villegas, en 1519, se publica en Burgos una obra titulada Remedio de jugadores, cuyo autor es fray Pedro de Covarrubias ${ }^{55}$, texto que bien refleja la profunda preocupación de los moralistas de aquellos años ante lo que había llegado a ser una patológica inclinación al juego de azar.

Otra prueba que confirma la peligrosidad del problema para nuestro arcediano es un recuerdo personal que Villegas trae a la memoria de un suceso que le causó gran impresión, una anécdota ejemplar que da mayor fuerza a su mensaje:

acaezció en mis tiempos de uno que, haviendo jugado y perdido quanto tenía se aforcó, y yo, seyendo mochacho, le fui a ver y el alcalde le havía mandado atar unos naipes colgados del pescueço y fecho poner dados en las manos, y ansí le

\footnotetext{
${ }^{51}$ Canto XIII, copla XVIII.

${ }^{52}$ Canto XIII, copla XVIII.

${ }^{53}$ Canto XI, copla VII.

${ }^{54}$ Sobre este aspecto véase A. C. Ibáñez Pérez (1990), pp. 291-296.

55 P. de Covarrubias (1519). Una información detallada sobre esta edición en M. Fernández Valladares (2005), I, pp. 492-493.
} 
fizo estar todo aquel día que no le quitasen, y todo el mundo le iva a ver, ansí puesto en su cadira de honor ${ }^{56}$.

Es éste un buen testimonio de la viveza y de la plasticidad de la narración de Villegas que, a través de detalles macabros, se esfuerza por cargar de dramatismo sus versos y su glosa. Si el extremado realismo de las penas y del sufrimiento de los dañados es una característica de la representación dantesca en el Inferno ${ }^{57}$, en la traducción y en el comentario castellano el poder de las imágenes es aún más impactante.

VI. Otro canto fundamental por lo que atañe al ámbito económico es sin duda el $\mathrm{XVII}$, en el que se presenta la categoría de los usureros ${ }^{58}$. Nos encontramos en el tercer girón del séptimo círculo, pues los usureros pertenecen a la categoría de los violentos contra el arte, es decir, contra el trabajo, la peor categoría de violentos. La usura es un problema que acucia insistentemente a Dante, como demuestran varios tercetos del ya citado canto XI, donde el viator pide a su guía Virgilio que le explique por qué la usura ofende la divina bondad (vv. 91-96): la respuesta del vate mantuano defiende la estirpe divina del trabajo, que sigue a la naturaleza, hija de Dios, y por lo tanto puede considerarse nieto de Dios. Como manda la Sagrada Escritura, el hombre tiene que sustentarse con el trabajo: el usurero, que saca provecho del dinero, ofende a la hija, al nieto de Dios y, a la vez, a Dios mismo (vv. 97-111). Aprovechando la larga y elaborada explicación de Virgilio, en su glosa Villegas utiliza una imagen de gran impacto, señalando que

el usurario es enemigo de naturaleza y estragador del arte humana de vevir, una bestia sedienta que beve la sangre del necesitado, que por la necesidad en que está le vende el uso del dinero que no tiene uso [...] el tal usuario va fuera del camino natural y del camino que la humana y virtuosa manera de vevir ha de llevar ${ }^{59}$.

Villegas juzga negativamente la postura de Landino, que en su opinión no dedica la justa atención al problema ("se pasa sin dezir quasi nada"). Pero, además, la reflexión del burgalés acerca de la usura es muy interesante por su recaída léxica, ya que nuestro arcediano recuerda que:

ha se de saber que en nuestra lengua castellana, como no tenemos este vocablo mutuo, llamámoslo enpréstido, y en la verdad es muy diferente, porque

\footnotetext{
${ }^{56}$ Canto XIII, copla XVIII.

${ }^{57}$ Sobre este aspecto véase sobre todo E. Auerbach (1963), pp. 99-102.

${ }^{58}$ G. Padoan (1982); M. Aversano (2011); E. Bigi (2000); G. Gorni (2000); G. Roellenbleck (2002).

${ }^{59}$ Canto XI, copla XVII.
} 
emprestarse puede la mula y la ropa y las otras cosas, de las quales el amigo puede usar, y son nuestras en la propriedad, así que le damos el uso de aquellas cosas y retenemos el dominio. Hay cosas que no se pueden emprestar sin se dar el uso y propriedad enteramente, como es el dinero y trigo y vino y las cosas que consisten en número y peso y medida, y son de qualidad que el uso las consume, y de aquéllas no hay uso, porque su uso es su consumpción, y usándolas se acaban, y en éstas no es empréstido, sino mutuo, que quiere dezir que lo mío se fizo tuyo, que enprestándote diez florines o diez fanegas de trigo, luego aquello se fizo tuyo y no eres obligado a me lo tornar lo mesmo [...] Mostró en esto naturaleza humana no dando uso en estas cosas; querer que se mutuasen entre los hombres graciosamente y sin interese, como conviene a la hermandad [...] y por esto se dixo arriba que el usurario faze contra natura, que quiere fazer uso y venderle donde no le hay [...] así quel vocablo castellano nuestro que dezimos prestar dize bien en las cosas que tienen uso como la ropa y la casa, lo qual dándolo graciosamente para que lo use es emprestar, y podémoslo dar por precio, y estonces es alquilar. Concuerda bien el prestar con el mutuar, en quanto se faze graciosamente y sin precio, mas hay diversidad en el pasar del dominio, que el empréstido le puede retener, el mutuo no, que como diximos de lo mío se fizo tuyo, y en dándose el dinero o el trigo o el vino lo fize tuyo, y dándote el uso te di la propriedad ${ }^{60}$.

Por lo que atañe a la usura, en la glosa castellana menudean las referencias a la Sagrada Escritura (la célebre frase de Lucas 6 34-35, "Mutuum date, nihil inde sperantes”, así como Levítico 25, 37 y Ezequiel 18, 13) donde, a diferencia de otros pecados, no hay contradicción o incertidumbre en la condena. En esta constante recuperación de fragmentos bíblicos Villegas se demuestra enganchado todavía a ciertos hábitos mentales y culturales medievales: en línea general el hombre de la Edad Media suele buscar en la Sagrada Escritura el origen y la explicación de todo fenómeno, aunque esta actitud no será rara entre los humanistas castellanos de los siglos de oro.

La reflexión léxica de Villegas sobre la usura revela la lectura de las obras lexicográficas de Palencia y Nebrija y en cierto modo anticipa lo que dirá, casi un siglo después, Covarrubias en el Tesoro de la lengua castellana o española (1611). En su Vocabulario Nebrija no acoge la entrada "mutuo", estableciendo además una clara diferencia entre dos distintos préstamos: el "emprestar lo que se buelve”, procedente del verbo latino accomodo-as, y el "emprestar lo que no se buelve", procedente de mutuo-as. Así las cosas, el préstamo del primer tipo deriva del sustantivo latino accomodatum-i, el del segundo tipo deriva de mutuus ${ }^{61}$. Tampoco en el Universal vocabulario de Palencia se halla el sustantivo “mutuo”, pues leemos que la palabra es "adverbio [...] emprestando o trocando y es [...] conmutar

${ }^{60}$ Canto XVII, copla IX.

${ }^{61}$ E. A. de Nebrija (1981), p. 86. 
quantidad o afecto de un hombre a otro" 62 . La voz "mutuo" no aparecerá tampoco en el Tesoro de Covarrubias, cuya entrada "emprestar" presenta además cierta analogía con la reflexión de Villegas: "hay algunas cosas que aunque se presten, no se vuelven ellas mesmas porque se consumen, sino otras de su género, como el trigo, la cebada y también el dinero, volviendo el oro en oro y la plata en plata, etc" ${ }^{\prime 3}$.

VII. El problema del dinero relacionado con la Iglesia es el eje de Inferno XIX, el canto de los pontífices simoniacos ${ }^{64}$. En la concepción dantesca la simonía es un pecado que, al igual que la avaricia de los clérigos, va más allá de cualquier límite temporal, siendo la traición más evidente de la misión espiritual de la Iglesia, esposa de Jesús. La metáfora nupcial caracteriza el canto, pues si los malos pontífices han traicionado "le cose di Dio, che di bontate/ deon esser spose" (vv. 23), Bonifacio VIII es el marido que ha engañado a "la bella donna", es decir a la Iglesia (vv. 55-57). La codicia desenfrenada de los papas, interesados sólo en el poder temporal, les ha llevado a apropiarse de los bienes y de los derechos del Imperio, privando al hombre de la paz. El tono con el que arranca el canto es solemne, con la firme invectiva que Dante dirige a los secuaces de Simón Mago, que pidió a los apóstoles que le concedieran por dinero la capacidad de bautizar.

Recogiendo fielmente lo que había afirmado Landino ${ }^{65}$, Villegas señala que

simonía es venta o compra de las cosas sagradas y espírituales con dinero o con cosa equivalente, así que él que compra o vende los sacramentos o dignidades o beneficios o qualquiera otra cosa espíritual es simoniaco, porque las tales cosas no tienen precio de oro, ni de plata, mas de sciencia de vida de buenas constumbres y de virtud ${ }^{66}$.

Aquí también el arcediano de Burgos construye su argumentación a partir de numerosas referencias a san Agustín, san Jerónimo y santo Tomás, que con firmeza condenaron este vil oficio; aprovechar lo espiritual para enriquecerse, práctica común entre los pontífices, es intolerable. En opinión de Villegas la simonía roza la

\footnotetext{
${ }^{62}$ A. de Palencia (1490), fol. cclxxxxv.

${ }^{63}$ S. De Covarrubias (2006), p. 768.

${ }^{64}$ C . Singleton (1965); K. Foster (1977); D. Nolan (1977); R.B. Herzman- W. A. Stephany (1978); D. Della Terza (1990); I.Borzi (1994); G. Muresu (2009).

65 "è simonia vendita o compera delle chose sacre et spirituali con denari et chon chose equivalenti a denari. Adunque chi vende o compera e sacramenti della chiesa, o alcuna dignità spirituale, o beneficii, o altre chose simili, delle quali el vero prezo è non oro né argento, ma sanctità di vita et di costumi, et virtú, et doctrina, è simoniaco”. C. Landino (2001), II, p. 749.

${ }^{66}$ Canto XIX, copla I.
} 
herejía, pues quien considera los sacramentos como algo comprable o vendible es sin lugar a dudas un infiel ${ }^{67}$. Como ocurre otras veces, en la glosa Villegas acerca el texto dantesco a la realidad de la Castilla actual, apoyándose en la autoridad del derecho canónico:

las penas de los simoniacos son grandes y muchas en los derechos establescidas contra ellos: son obligados a restitución de quanto llevan de los beneficios, han de ser privados dellos, son suspensos de las órdenes y no pueden ministrar en ellas, son descomulgados por muchas constituciones apostólicas de romanos pontífices, son infames y inábiles para los otros beneficios ${ }^{68}$.

Al igual que en el canto VII, también aquí los versos presentan una amplificación de corte moral estrechamente relacionada con el mal uso del dinero: al traducir los tercetos en los que Dante reprocha duramente a Nicolás III la práctica de la simonía, Villegas añade un verso

Sea vuestra pecunia con vós en tristura (XIVe)

cuyo sentido aclara en el comentario, señalando que la amplificación se funda sobre la autoridad de la Sagrada Escritura, eso es, sobre las palabras que san Pedro dijo a Simón Mago en los Actos de los Apóstoles (VIII, 20): "pecunia tua tecum sit in perditione”.

Si a propósito de la usura Villegas había descartado en parte la exégesis de Landino, en el canto XXI elige utilizar como punto de referencia para explicar el pecado de la baratería el Comento, aunque la definición del arcediano de Burgos presenta elementos distintos de la del humanista toscano: "baratería es véndida o compra de aquello que por virtud y caridad y hermandad humana graciosamente se

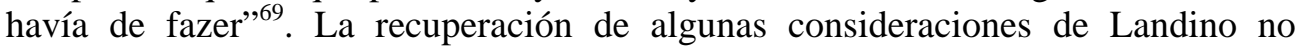
impide a Villegas añadir reflexiones autónomas: muy personales son las comparaciones que el traductor dantesco hace entre los barateros y los corsarios antes y los cazadores después:

67 "no siente bien de los sacramentos el que los compra y los faze venales como otra mercadería; falta de fe es y grand indicio de infidelidad, así estos títulos de heregía y simonía juntos se ponen en los textos del derecho canónico”. Canto XIX, copla I.

${ }^{68}$ Canto XIX, copla I.

${ }^{69}$ Canto XXI, copla I. La diferencia más notable estriba en el hecho de que, si Villegas emplea un léxico relacionado con el Cristianismo, "virtud y caridad y hermandad”, el término que usa Landino, “officio”, insiste más en el daño civil y social que hace quien practica la baratería: "Baratteria è vendimento o comperamento di quello che per proprio officio si debba fare sanza prezo, et vendesi chosì la giustitia chome la ingiustizia”. C. Landino (2001), II, p. 785. 
el baratero guerra, pregona contra todo próximo amigo o enemigo, de todos ha de sacar y a toda ropa faze como el buen cosario [...] Son semejantes los barateros a los caçadores de lobos o de otras bestias fieras que fazen foyas y cúbrenlas de foyas y ramas para que no se vean; así cubre el baratero su maldad con demostración de verdad y amicicia ${ }^{70}$.

El tono de Villegas es muy agresivo, la condena firme, aunque la segunda comparación, más que a los barateros, se adaptaría mejor a los hipócritas.

VIII. Finalmente, mucho más en profundidad, encontramos otra categoría de pecadores relacionada con el dinero o, mejor dicho, con la moneda: me refiero a los falsificadores, entre los quienes destaca la figura de Maestro Adamo (canto XXX), el monedero que adulteró los fiorini de Florencia $^{71}$. La tremenda pena de los falsarios, la hidropesía, atestigua la gravedad del pecado en la concepción dantesca: Dante sigue la estela de una tradición muy arraigada en la literatura cristiana, pues ya los Padres de la Iglesia veían una estrecha relación entre la enfermedad de la hidropesía y la avaricia, asociación que, como ya señaló Curtius, se encuentra en muchos autores de la Edad Media (Abelardo, Alano de Lille, Gautier de Chatillon). Con posterioridad a Villegas, en la España del Siglo de Oro menudean ejemplos de esta imagen de la hidropesía como sed morbosa: la metáfora se encuentra por ejemplo en Gracián (Criticón, I 136), Góngora (Soledad I 108) y Calderón (La vida es sueño, acto I, escena IV $)^{72}$.

$\mathrm{Al}$ igual que Landino, Villegas no parece sentir la influencia patrística ya que no hace ninguna referencia a la asociación entre hidropesía y avaricia; aunque dedique unas palabras a explicar el carácter de la enfermedad, causadora de una sed desesperada, el arcediano de Burgos no se detiene en explicar por qué Dante representa a los falsificadores como hidrópicos ${ }^{73}$.

En el texto dantesco, las palabras de Maestro Adamo revelan el uso de un léxico bastante específico de la numismática, “batter li fiorini/ ch’avevan tre carati di mondiglia” (vv. 89-90), frase con la que el pecador aclara cómo llevó a cabo la adulteración de la moneda ${ }^{74}$ y que Villegas traduce muy ad verbum, "batir los florines/ que habían tres carateres de la mondilla"75. Si el célebre fiorino de

\footnotetext{
${ }^{70}$ Canto XXI, copla I.
}

${ }^{71}$ D. Heilbronn (1983); R. Dragonetti (2000); G. Contini (2001); V. Bartoli- P. Ureni (2002); E. Fenzi (2005).

${ }^{72}$ E. R. Curtius (1955), I, p. 395.

${ }^{73}$ Sin embargo, los primeros comentarios dantescos señalaban esta relación, pues Pietro Alighieri, apoyándose en Lucas 14,2, considera la hidropesía típica de los avaros codiciosos de oro. P. Alighieri (2002), p. 252.

${ }^{74}$ Sobre este aspecto véase G. Alonzo (2010), p. 83.

${ }^{75}$ Canto XXX, copla XIV. 
Florencia $^{76}$, aparecido en 1252 y cuyo periodo de auge duró hasta la crisis de 1340, estaba hecho de oro puro (24 quilates), Maestro Adamo, empujado por los condes Guidi di Romena, acuña una moneda utilizando tres quilates de metal de bajo valor.

Aunque el problema de los falsificadores sea uno de los que más acucia la conciencia de Dante, en el comentario castellano no se evidencia igual atención. En primer lugar la información biográfica que Villegas proporciona a propósito de Maestro Adamo es muy escasa ${ }^{77}$ y se funda totalmente en lo que Landino dice en el Comento. Además, en la glosa castellana falta la percepción de la peligrosidad del pecado, que Dante considera no sólo una traición de la comunidad civil, sino también una profanación del símbolo por excelencia de Florencia, el fiorino, embajador de la ciudad con su imagen del lirio y de San Juan Bautista, pues el mismo Maestro Adamo recuerda con una rebuscada perífrasis que "falsai/ la lega suggellata del Batista” (If. XXX 73-74). El pecador ha falsificado no sólo el objeto, la moneda: él ha traicionado el antiguo y sagrado vínculo entre la ciudad de Florencia y su santo patrón.

Con respecto a eso, hay que señalar que sobre todo los primeros comentadores del poema dantesco hicieron hincapié en la gravedad del pecado: Benvenuto da Imola, por ejemplo, notaba que si un falsario de monedas peca graviter, un falsario del fiorino peca gravissime ${ }^{78}$. En el Comento, la condena del pecado aparece menos firme, lo que determina una glosa muy pobre en Villegas, que no dedica ni siquiera una palabra a los versos dantescos. Quizá esta escasa atención al problema de la falsificación de la moneda se deba al hecho de que, cuando llega a la imprenta su obra, no existía una unidad monetaria en la Península Ibérica, pues en Castilla seguía circulando el maravedí (que en siglo XVI ya no se acuña), en Aragón el dinero. A pesar de que uno de los signos de la renovación política de los Reyes Católicos fue la búsqueda de una unificación del sistema monetario, al menos en Castilla $^{79}$, en Villegas no se evidencia una identificación con el objeto de la moneda, no hay, a diferencia de Dante, la visión de la moneda como algo sagrado.

${ }^{76}$ Sobre este aspecto véanse M. Bernocchi (1976), III, pp. 55-123; C. M. Cipolla (1990), p. 168; P. Spufford (1991), p. 232; R. Goldthwaite (1994), pp. 11-13; P. Grierson (2006), pp. 415-420.

77 “Este Adán fue natural de Brexa, grand monedero y maestro singular en aquella arte [...] Fue rogado por los condes de Romeña que falsasen los ducados de Florencia que tienen del un cabo a sant Juan Baptista [...] y éste, movido de codicia, lo fizo [...] Fue descubierto como todas estas maldades al fin se descubren y venido en manos de florentines le quemaron. Canto XXX, copla IX.

${ }_{78}$ Benvenuto da Imola (1887), II, p. 431. Sobre este aspecto, véase G. Alonzo (2010), p. 86.

${ }^{79}$ M. Fernández Álvarez (1989), I, pp. 110-111. Sobre la reforma monetaria de los Reyes Católicos, véanse entre otros P. Chaunu (1976), pp. 30-35; A. García Sanz (2007), p. 224. 
IX. La traducción del Inferno de Villegas y su monumental comentario representan un momento fundamental del dantismo hispánico: el elemento de mayor originalidad de los versos de arte mayor estriba en la autonomía que el traductor demuestra con respecto al texto dantesco, mientras que, por lo que atañe a la glosa, Villegas no se limita a una pasiva recuperación de la exégesis de comentadores anteriores, en primer lugar Landino, manifestando a menudo una opinión personal acerca de múltiples problemas de la Comedia. Hemos visto que, a propósito del orden de las penas de los pecadores relacionados con el dinero, el traductor suele actualizar el texto italiano, utilizando asuntos (la conquista de ultramar, la plaga del juego de azar) más directamente ligados a la realidad de la Castilla del primer tercio del siglo XVI, con vistas a que el público castellano entienda el sentido profundo del mensaje dantesco.

Villegas, fiel portavoz de las tendencias del humanismo del clero catedralicio burgalés impulsado en el siglo XV por Alfonso de Cartagena, a veces critica los pasajes del Inferno en los que, en su opinión, el poeta toscano no ha respetado escrupulosamente el dogma, creando una representación poética cuya originalidad es demasiado desenvuelta. Sin embargo, por lo que respecta al tema del dinero y de las perniciosas consecuencias de la sed de riquezas, la posición del traductor es muy parecida a la de Dante: la distancia, tanto temporal como geográfica, entre la Florencia de finales del siglo XIII y la Burgos del comienzo del XVI se reduce significativamente, llegando casi a desaparecer. Publicada más de dos siglos después del Inferno, la obra de Villegas es una dramática y alarmante denuncia de la gravedad del mal uso del dinero, un pecado intemporal que el arcediano de Burgos, al igual que san Pablo y Dante, considera "raíz de todos los males".

\section{Obras citadas}

AlighIERI, Pietro: Comentum super poema Comedie Dantis, Tempe, Arizona Center for Medieval and Renaissance Studies, 2002.

Alonzo, Giuseppe: "Numismatica dantesca. La Commedia tra santificazione e maledizione della moneta”, en Stella forte. Studi danteschi, Nápoles, D’Auria, 2010, pp. 81-105.

Alvar, Carlos: "Notas para el estudio de las traducciones italianas en Castilla durante el siglo XV", Anuario Medieval, 2 (1990), pp. 23-41.

Alvar, Carlos- LuCíA Megías, José Manuel: Repertorio de traductores del siglo $X V$, Madrid, Ollero y Ramos, 2009.

ARCE, Joaquín: "La lengua de Dante en la Divina Commedia y en sus traductores españoles”, Revista de la Universidad de Madrid, 14 (1965), pp. 9-48.

AuERBACH, Erich: Studi su Dante, Milán, Feltrinelli, 1963.

Aversano, Mario: Un nuovo Dante, Atripalda, Il Calamaio, 1992.

AVERSANO, Mario: "Il canto XVII dell'Inferno", en Lectura Dantis 2002-2009, 
Nápoles, L’Orientale Editrice, 2011, II, pp. 659-681.

BARANSKI, Zygmunt: "La lezione esegetica di Inferno I: allegoria, storia e letteratura nella Commedia”, en Dante e le forme dell'allegoresi, Ravenna, 1987, pp. 79-98.

BARBI, Michele: Della fortuna di Dante nel secolo XVI, Pisa, Nistri, 1890.

BARDAZZI, Giovanni: “Avari e prodighi, iracondi e accidiosi”, Studi Danteschi, LXV (2000), pp. 1-39.

BARTOLI, Vittorio- UrenI, Paola: "La malattia di Maestro Adamo", Studi Danteschi, LXVII (2002), pp. 99-116.

Beltrani, Armida: "Don Pedro Fernández de Villegas e la sua traduzione della prima Cantica della Divina Commedia”, Giornale Dantesco, 23 (1915), pp. 254-283.

Benvenuto DA Imola, Comentum super Dantis Aldigherij Comoediam, Florencia, Barbera, 1887.

BERNOCCHI, Mario: Le monete della repubblica fiorentina, Florencia, Olschki, III, 1976.

BIGI, Emilio: "Realismo e retorica nel canto XVII dell'Inferno", Studi Danteschi, LXV (2000), pp. 87-99.

BoRZI, Italo: "Il canto XIX dell'Inferno", L'Alighieri. Rassegna bibliografica dantesca”, XXXV (1994), pp. 7-26.

CARDINI, Roberto: La critica del Landino, Florencia, Sansoni, 1973.

CARRERA DíAZ, Manuel: "Le traduzioni spagnole della Divina Commedia”, Letture Classensi, 21 (1992), pp. 21-34.

CIPOLLA, Carlo Maria: Il governo della moneta a Firenze e Milano nei secoli XIVXVI, Bolonia, Il Mulino, 1990.

Chaunu, Pierre: La España de Carlos V II. La coyuntura de un siglo, Barcelona, Península, 1976.

ConTini, Gianfranco: Un’idea di Dante, Turín, Einaudi, 2001.

COVARRUBias, Pedro de: Remedio de jugadores, Burgos, Alonso de Melgar, 1519.

COVARRUBIAS, Sebastián de: Tesoro de la lengua castellana o española, Madrid, Iberoamericana, 2006.

CuRTIUS, Ernst Robert: Literatura Europea y Edad Media Latina, México-Buenos Aires, Fondo de Cultura Económica, 1955.

CUSANI, Emma: Il grande viaggio nei mondi danteschi, Roma, Mediterranee, 1993.

Della TerzA, Dante: "Inferno XIX", in Dante's Divine Comedy. I. Inferno, Charlottesville, 1990, pp. 247-261.

DiONISOTTI, Carlo: “Dante nel Quattrocento”, en Atti del Congresso internazionale di studi danteschi, I, Florencia, Sansoni, 1965-1966, pp. 333-378.

DragonetTI, Roger: "L'hydropisie du faux-monnayeur dans la Divine Comédie", en Genève et l'Italie, Ginebra, Société genevoise d'études italiennes, 2000, pp. 323-352.

ELLIOTT, John H.: España, Europa y el mundo de Ultramar (1500-1800), Madrid, 
Taurus, 2010.

FARINELLI, Arturo: Dante in Spagna-Francia-Inghilterra-Germania, Turín, Bocca, 1922.

FENZI, Enrico: "Il canto XXX dell'Inferno", Quaderns d'Italià. Departamiento de filologìa francesa i romanica. Area de filologìa italiana, X (2005), pp. 171193.

FERNÁNDEZ ÁlVAREZ, Manuel: La sociedad española en el Siglo de Oro, Madrid, Gredos, 1989.

Fernández De Villegas, Pedro: La tradución del Dante de lengua toscana en verso castellano, Burgos, Fadrique Alemán, 1515.

FERNÁNDEZ VALLADARES, Mercedes: La imprenta en Burgos (1501-1600), Madrid, Arco Libros, 2005.

FIGURELLI, Fernando: "Il canto VII dell'Inferno", Studi danteschi, LIV (1983), pp. 121-146.

Floranes, Rafael de: "Memorias del Doctor Don Pedro Fernández de Villegas, Arcediano de Burgos", Colección de documentos inéditos para la Historia de España, 19 (1851), pp. 408-435. FOSTER, Kenelm: "The Canto of the damned Popes, Inferno XIX”, en The two Dantes and other studies, 1977, pp. 86-106.

GARCía SANZ, Ángel: La economía española en la época de los Reyes Católicos (1474-1516), en Comercio y hombres de negocios en Castilla y Europa en tiempos de Isabel la Católica, Burgos, Sociedad Estatal de Conmemoraciones Culturales, 2007, pp. 211-228.

GARIN, Eugenio: "Dante nel Rinascimento”, Letture Classensi, 3 (1970), pp. 111143.

GARIN, Eugenio: Medioevo y Renacimiento, Madrid, Taurus, 1981.

GARIN, Eugenio: L'umanesimo italiano, Roma-Bari, Laterza, 1994.

GETTO, Giovanni: Aspetti della poesia di Dante, Florencia, Sansoni, 1966.

GolDTHWAITE, Richard A.: Studi sulla moneta fiorentina: secoli XIII-XVI, Florencia, Olschki, 1994.

GoRNI, Guglielmo: “Canto XVII”, in Lectura Dantis Turicensis. Inferno, Florencia, Franco Cesati, 2000, pp. 233-241.

GrIERSON, Philip: “Il fiorino d'oro: la grande novità dell'Occidente medievale”, Rivista italiana di numismatica”, CVII (2006), pp. 415-420.

HAMLIN, Cinthia: "Fernández de Villegas y Landino, traducción y reapropiación, el caso de la dicotomía vida activa-vida contemplativa en el Comentario de la Comedia”, Ehumanista, 20 (2012a), pp. 430-450.

HAMLIN, Cinthia: "El comentario de la Divina Comedia de Fernández de Villegas: características generales y actitudes humanistas”, Ehumanista, 21 (2012b), pp. 437-466.

HAMLIN, Cinthia: "La traducción en la España pre-humanista y sus causas políticoideológicas: el caso de la Divina Commedia y los Reyes Católicos”, 
Revista de Literatura Medieval, 24 (2012c), pp. 81-100.

HeILBRONN, Denise: "Master Adam and the fat-bellied lute (Inf. XXX)", Dante Studies, CI (1983), pp. 51-66.

HERZMAN, Ronald B.- STEPHANY, William A.: "O miseri seguaci: sacramental inversion in Inferno XIX”, Dante Studies, XCVI (1978), pp. 39-65.

IBÁÑEZ PÉREZ, Alberto C.: Burgos y los burgaleses en el siglo XVI, Burgos, Exc.mo Ayuntamiento de Burgos, 1990.

LA BRASCA, Frank: "Du prototype à l'archétype: lecture allégorique et réécriture de Dant dans et par le commentaire de Cristoforo Landino", en Scritture di scritture. Testi, generi, modelli nel Rinascimento, Roma, Bulzoni, 1987, pp. 69-107.

LANDino, Cristoforo: Comento sopra la Comedia, Roma, Salerno Editrice, 2001.

LEDDA, Giuseppe: "Inferno VII”, en Lectura Dantis Bononiensis. II, Bolonia, Bolonia University Press, 2012, pp. 59-87.

LÓPEZ VidRIero, María Luisa- SANTiago PAEz, Elena: "Dante, Petrarca e Boccaccio in castigliano: i rapporti tra Italia e Spagna nella stampa e nell'illustrazione del libro", en La stampa in Italia nel Cinquecento, Atti del Convegno di Roma (17-21 ottobre 1989), II, Roma, Bulzoni, 1992, pp. 719742.

MARIANI, Andrea: “danaro”, en Enciclopedia Dantesca, II, Roma, Istituto della Enciclopedia Italiana, 1970, p. 302.

MARTI, Mario: Realismo dantesco e altri studi, Milán-Nápoles, Ricciardi, 1961.

MERCURI, Roberto: “Comedía di Dante Alighieri”, en Letteratura italiana, II. Le Origini, il Duecento, il Trecento. Le opere, Turín, Einaudi, 2007, pp. 301470.

MondolA, Roberto: Dante nel Rinascimento castigliano L'Infierno di Pedro Fernández de Villegas, Nápoles, Pironti, 2011.

MuRESU, Gabriele: "Sulla pena dei simoniaci”, L'Alighieri. Rassegna dantesca, XXXIII (2009), pp. 81-91.

NEBRIJA, Elio Antonio de: Vocabulario de romance en latín, Madrid, Castalia, 1981.

Nolan, David: “Inferno XIX”, en Dante Commentaries, Dublino, 1977, pp. 7-42.

PADOAN, Giorgio: “Canto XVII dell'Inferno", en Lectura Dantis Neapolitana, Nápoles, Loffredo, 1986, pp. 287-300.

PALENCIA, Alfonso de: Universal vocabulario de romance en latín, Sevilla, 1490.

PARKER, Deborah: Commentary and ideology, Dante in the Renaissance, DurhamLondres, Duke University Press, 1993.

PenNa, Mario: "Traducciones castellanas antiguas de la Divina Comedia”, Revista de la Universidad de Madrid, 14 (1965), pp. 81-127.

PeÑA PÉREZ, Francisco Javier: "La ciudad de Burgos en tiempos de Isabel la Católica. Sombras de una historia brillante", en Comercio y hombres de negocios en Castilla y Europa en tiempos de Isabel la Católica, Burgos, 
Sociedad Estatal de Conmemoraciones Culturales, 2007, pp. 229-250.

PROCACCIOLI, Paolo: Filologia ed esegesi dantesca nel Quattrocento. L'Inferno nel Comento sopra la Comedia di Cristoforo Landino, Florencia, Olschki, 1989.

QUAIN, Edwin A.: The Medieval accessus ad auctores, Nueva York, Fordham University Press, 1986.

RECIO, Roxana, "Landino y Fernández de Villegas: análisis de una traducción del Infierno de Dante”, Voz y Letra. Revista de Literatura, 10 (1999), pp. 25-39.

RODRÍGUEZ VELASCO, Jesús: "La biblioteca y los margenes. Ensayo teórico sobre la glosa en el ámbito cortesano del siglo XV en Castilla”, Ehumanista. Journal of Iberian Studies, 1 (2001), pp. 119-134.

RoelLenBleck, Georg: "Lectura Dantis: Inferno XVII", Deutsches DanteJahrbuch, LXXVII (2002), pp. 45-60.

RUSSELL, Peter: Traducciones y Traductores en la Península Ibérica (1400-1550), Bellaterra, Publicacions de la Universitat Autònoma de Barcelona, 1985.

SÁNCHEZ GARCíA, Encarnación- MONDOLA, Roberto: "Burgos 1515: cultura rinascimentale e ricezione della Comedía”, en Lectura Dantis 2002-2009, Nápoles, L’Orientale, 2011, IV, pp. 1387-1415.

SANTORO, Mario: “Cristoforo Landino e il volgare”, Giornale Storico della Letteratura Italiana, 131 (1954), pp. 501-547

SCOLARI, Antonio: “Canto XXI", en Lectura Dantis Scaligera, Florencia, Le Monnier, 1967, pp. 725-760.

SingLeTON, Charles: "Inf. XIX: “O Simon Mago!”, Modern Language Notes, LXXX (1965), pp. 92-99.

SoldATI, Paolo: "Canto XVII", en Lectura Dantis Scaligera, Florencia, Le Monnier, 1967, pp. 563-582.

SPUFFORD, Peter: Dinero y moneda en la Europa medieval, Barcelona, Crítica, 1991.

Thompson, David: “Landino’s life of Dante”, Dante Studies, 88 (1970), pp. 119127.

VICKREY, John F.: "Inferno VII: deathstyles of the rich and famous", Neophilologus, LXXIX (1995), pp. 599-610.

VILAR, Pierre: Oro e moneta nella storia, Bari, Laterza, 1971. 